\title{
IoT Based Ambulance Alert System for Geriatric people
}

\author{
Lavanya S, Madhumitha M, Srividhya R, Srividhyasakthi V
}

\begin{abstract}
Geriatric people are more prone to physiological imbalances due to the effect of aging. They face many problems in their day to day life which are needed to be solved before any serious complication arises. Most of the geriatric people are not getting adequate healthcare especially in case of old age homes the manager has to visit them in person to check their condition. Thus, providing them with remote and quick access to healthcare has become crucial. Our work focuses on, design of Internet of Things based vital parameter monitor for geriatric people along with Ambulance alert system. This device helps the old age home managers to monitor the condition of the patients with the help of an application. Based on Internet of Things technology, the application gets the temperature and $\mathrm{SpO}_{2}$ data of a patient and in case of emergency, nearby ambulances are tracked and alerted to save the lives. In addition, it will also be useful for contactless monitoring of patients who are affected by COVID-19 virus.

Keywords: Geriatric People, Vital Parameter Monitor, Internet of Things, Ambulance Alert System, Contactless Monitoring.
\end{abstract}

\section{INTRODUCTION}

$\mathrm{I}_{\mathrm{n}}$ many of the old age homes, geriatric people are in rooms which are away from the control room and the manager has to visit the room and help the needy, this can consume time and cause more discomfort to the geriatric people. Patient monitors can monitor the vital parameters but are too costly and only used in hospitals. So, there is a need of a device which can monitor them continuously and send data to the care taker [4]. An effective way to monitor them is designing a vital parameter monitor which is always in contact with them without disturbing their daily activities, simultaneously tracking them. The proposed system can monitor the vital parameters and transmit the information along with the location via Internet of Things technology [7]. In case of emergency which is possible when the patient is outdoors the device can track the location and send the data

Manuscript received on May 05, 2021.

Revised Manuscript received on May 11, 2021.

Manuscript published on June 30, 2021.

* Corresponding Author

Lavanya S, Student, Department of Biomedical Engineering, Sri Ramakrishna Engineering College, Coimbatore, India Email: lavanya.1707063@srec.ac.in

Madhumitha M, Student, Department of Biomedical Engineering, Sri Ramakrishna Engineering College, Coimbatore, India Email: madhumitha.1707033@srec.ac.in

Srividhya R, Student, Department of Biomedical Engineering, Sri Ramakrishna Engineering College, Coimbatore, India Email: srividhya.1707055@srec.ac.in

Srividhyasakthi V*, Assistant Professor, Department of Biomedical Engineering, Sri Ramakrishna Engineering College, Coimbatore, India Email: srividhyasakthi.v@srec.ac.in

(c) The Authors. Published by Blue Eyes Intelligence Engineering and Sciences Publication (BEIESP). This is an open access article under the CC BY-NC-ND license (http://creativecommons.org/licenses/by-nc-nd/4.0/) to nearby ambulance. The device will surely be a boon to geriatric people who are in need of adequate healthcare

\section{WHY TEMPERATURE AND OXYGEN}

According to a research conducted by National Institute of Aging, for an older person, a body temperature of $95^{\circ} \mathrm{F}$ or low can cause many health problems, such as a heart attack, kidney problems, liver damage, or worse[12]. Patients older than 65 years or those with chronic disease who have fever represent a group at high risk for serious disease. Morbidity and mortality rates in this group are significant. From $70 \%-90 \%$ are hospitalized and $7-9 \%$ die within 1 month of admission.[10]. The risks of hypothermia are shown in Fig 1.
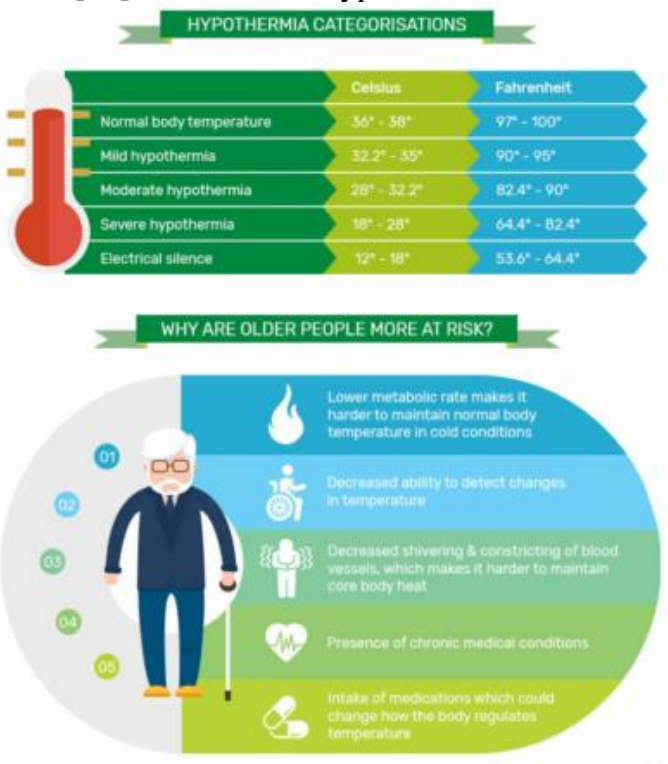

Fig 1-Risks of Hypothermia

blog.healthpropress.com/2019/02/how-to-prevent-hypother mia-in-older-people[13]

A study conducted by Keith S Kaye, Malini Stalam, Wendy E Shershen, Donald Kaye, suggests that in acutely infected nursing home patients, a decrease in oxygen saturation of $>3 \%$ from baseline, as well as a single oxygen saturation of $<\mathbf{9 4 \%}$, should suggest pneumonia.

If the oxygen saturation level falls below $90 \%$ and left unmonitored in particular for older people who are in sleep[11] it can lead to Hypoxemia which can even cause brain and liver damage. The effects of hypoxemia are shown in the below infographics (Fig-2). 


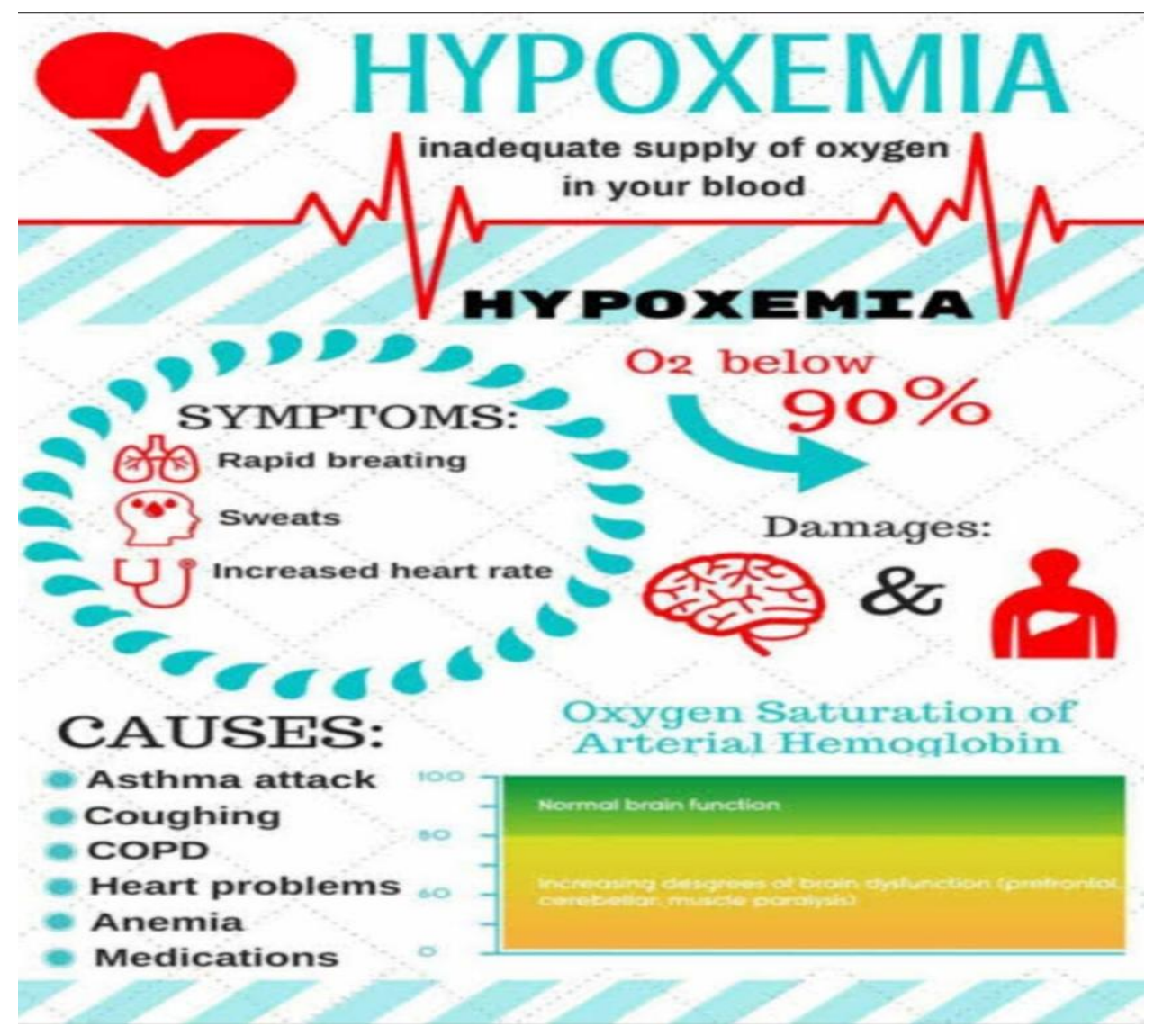

Fig 2- Hypoxemia-Symptoms and causes

Courtesy:

ation[14]

vivehealth.com/blogs/resources/what-is-normal-oxygen-satur

\section{COMPARISON WITH EXISTING PRODUCTS}

\begin{tabular}{|c|c|c|c|}
\hline PRODUCT & PARAMETERS MONITORED & ADVANTAGE & $\begin{array}{c}\text { NEED OF PROPOSED } \\
\text { PRODUCT }\end{array}$ \\
\hline Proposed Product & Temperature,SpO $\mathbf{S}_{2}$ & $\begin{array}{c}\text { IOT based Alert } \\
\text { Mobile application for easy User } \\
\text { interface }\end{array}$ & $\begin{array}{c}\text { Real time monitoring Sends } \\
\text { location of patient to } \\
\text { ambulance driver and vice } \\
\text { versa }\end{array}$ \\
\hline Snap ECG B10 & ECG and EKG & Continuous monitoring for 12 hours & $\begin{array}{c}\text { No any type of alert system } \\
\text { found in case of emergencies }\end{array}$ \\
\hline Health Watch & $\begin{array}{c}\text { ECG, temperature, respiratory } \\
\text { rate, body posture }\end{array}$ & Remote health monitoring & $\begin{array}{c}\text { No mobile application for easy } \\
\text { user interface }\end{array}$ \\
\hline
\end{tabular}

\section{Table 1-Comparison with existing products}

\section{MATERIALS}

This section includes selection of sensors and controllers for the development of IoT based ambulance alert system for geriatric people. The sensors and controllers were selected based on those meeting the specific requirements for the proposed system.

TEMPERATURE SENSOR (LM35)

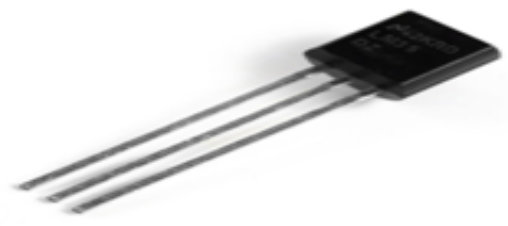

Fig 3- LM35 (Temperature Sensor) Courtesy: mikroe.com/lm35-sensor

Published By: Blue Eyes Intelligence Engineering and Sciences Publication (C) Copyright: All rights reserved.

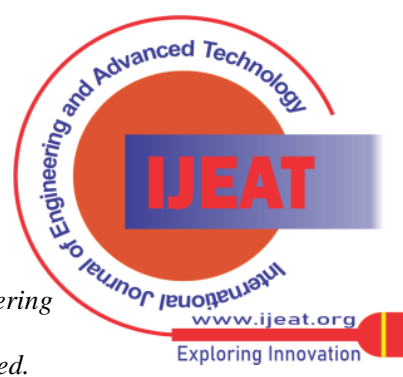




\begin{tabular}{|c|c|}
\hline PARAMETERS & VALUES \\
\hline Scale Factor & $\begin{array}{l}\text { Linear }+10.0 \\
\mathrm{mV} /{ }^{\circ} \mathrm{C}\end{array}$ \\
\hline Accuracy & $0.5^{\circ} \mathrm{C}$ \\
\hline Temperature & $-55^{\circ} \mathrm{C}$ to $150^{\circ} \mathrm{C}$ \\
\hline Operating voltage & $4 \mathrm{~V}$ to $30 \mathrm{~V}$ \\
\hline
\end{tabular}

Table 2- Specifications of LM35

$\mathrm{SpO}_{2}$ SENSOR(MAX30100)

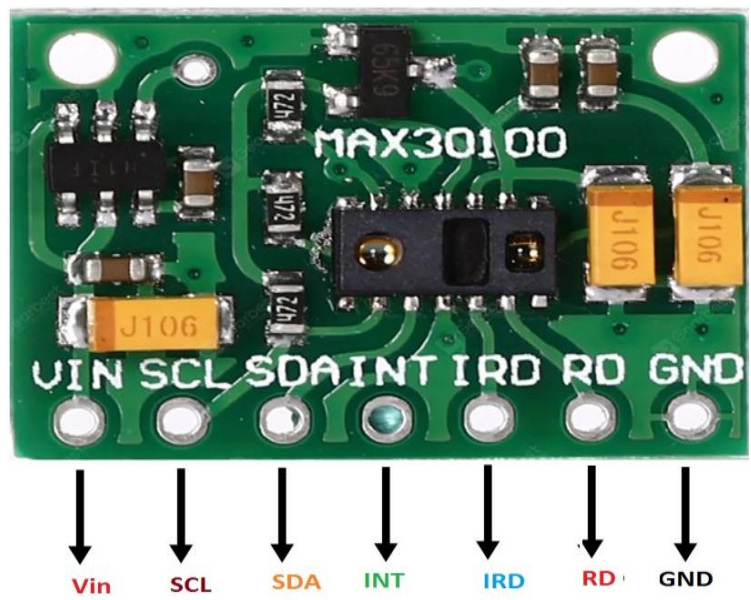

Fig 4- MAX30100 ( $\mathrm{SpO}_{2}$ Sensor)

Courtesy:

theengineeringprojects.com/2019/05/introduction-tomax301 00.html

\begin{tabular}{|c|c|}
\hline PARAMETERS & VALUES \\
\hline Operating voltage & $1.8 \mathrm{~V}$ and $3.3 \mathrm{~V}$ \\
\hline ADC Resolution & $14 \mathrm{bits}$ \\
\hline Digital band reject filter & $50 \mathrm{~Hz} / 60 \mathrm{~Hz}$ \\
\hline LED pulse width & $200 \mu$ s to $1.6 \mathrm{~ms}$ \\
\hline
\end{tabular}

Table 3-Specifications of $\mathrm{SpO}_{2}$ Sensor(MAX30100) GPS Module (Neo-6m)

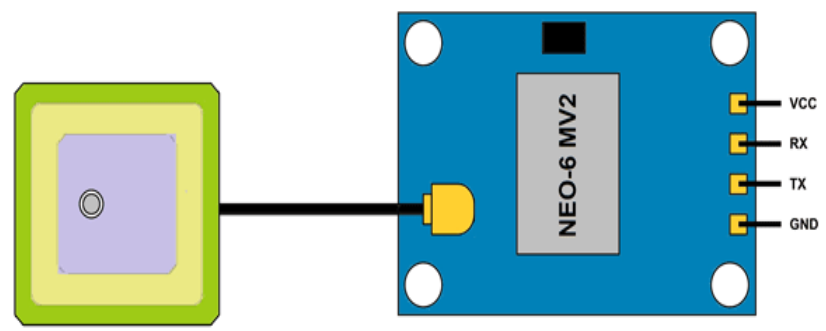

Fig 4- NEO-6M (GPS MODULE)

Retrieval Number: 100.1/ijeat.E25890610521 DOI:10.35940/ijeat.E2589.0610521

Journal Website: www.ijeat.org

\section{Courtesy:}

components101.com/modules/neo-6mv2-gps-module

\begin{tabular}{|l|c|}
\hline PARAMETERS & VALUES \\
\hline Reciever type & 50 channels \\
\hline Horizontal position accuracy & $2.5 \mathrm{~m}$ \\
\hline Velocity accuracy & $0.1 \mathrm{~m} / \mathrm{s}$ \\
\hline Operating voltage & $3.3 \mathrm{~V}$ \\
\hline
\end{tabular}

Table 4- Specifications of Neo-6m GPS Module

NODE MCU ESP8266

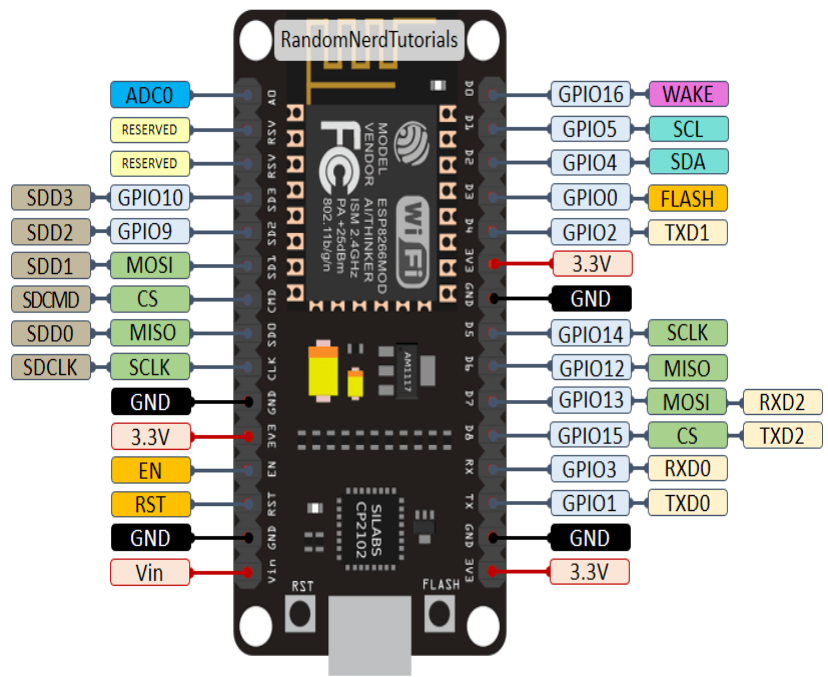

Fig 5- ESP8266 (NODE MCU)

\section{Courtesy:}

components101.com/development-boards/nodemcu-esp8266 -pinout-features-and-datasheet

\begin{tabular}{|c|c|}
\hline PARAMETERS & VALUES \\
\hline Input voltage & $7-12 \mathrm{~V}$ \\
\hline Clock speed & $80 \mathrm{MHz}$ \\
\hline Digital Input/Output Pins & 16 \\
\hline Operating voltage & $3.3 \mathrm{~V}$ \\
\hline
\end{tabular}

Table 5-Specifications of Node MCU ESP8266

Published By: Blue Eyes Intelligence Engineering and Sciences Publication (C) Copyright: All rights reserved.

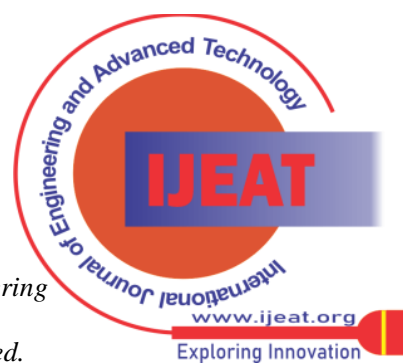




\section{METHODOLOGY}

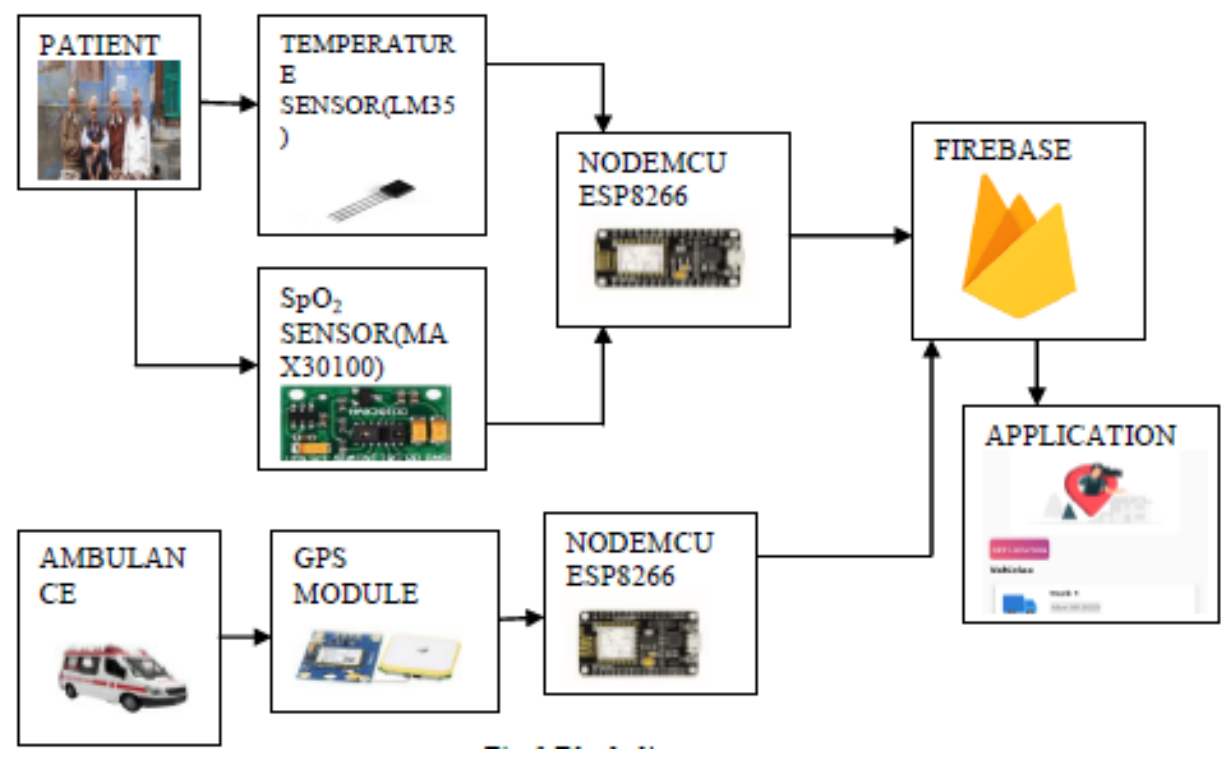

Fig 6-Block diagram

When homeostatic imbalance occurs, especially for geriatric people there are changes in temperature, oxygen saturation and heart rate. Temperature sensor has been used to measure temperature differences and for monitoring and measuring oxygen saturation, the $\mathrm{SpO}_{2}$ sensor has been incorporated along. These sensors are integrated using Internet of Things development board Node MCU ESP8266 and the software used is Arduino IDE (Version 1.8.8).To locates the nearby ambulances the GPS Module and a microcontroller Node MCU ESP8266 is used. The data is uploaded in a real-time database, Firebase and consequently it is transmitted to the designed application. The application tracks patient's health condition and it has smooth User interface with option to switch off the alert system if not required.

\section{RESULTS AND DISCUSSION}

Temperature and oxygen saturation were measured and recorded. Location of the ambulance was tracked and uploaded to firebase along with the data of vital parameters . These data will be sent to an application which monitors parameters and tracks the ambulance simultaneously. The application alerts the ambulance if the $\mathrm{SpO}_{2}$ range falls below or above the threshold value. The location of the ambulance will be received by the application and it also has the option to turn down the alert when the user does not require any emergency help of the ambulance

\section{CONCLUSION AND FUTUREWORKS}

Based on few trials with patients' consent we conclude that, the application monitors the vital parameters such as temperature and oxygen saturation using LM35 and MAX30100 accurately and it also obtains the ambulance location data successfully. On the whole, the monitoring system is very useful for the elderly in old age homes. In addition we believe that this device will also be useful for

Published By: Blue Eyes Intelligence Engineering and Sciences Publication (C) Copyright: All rights reserved.

COVID 19 patients who are in need of emergency health service with contactless monitoring. Further, we are currently in research to make the device wearable such that it would help to monitor existing parameters along with additional parameters such as ECG and respiratory rate of the elderly with better accuracy.

\section{REFERENCES}

1. Al-khafajiy, M., Baker, T., Chalmers, C., Asim, M., Kolivand, H., Fahim, M. and Waraich, A., 2019. Remote health monitoring of elderly through wearable sensors. Multimedia Tools and Applications, 78(17), pp.24681-24706.

2. Chen, M., Ma, Y., Song, J., Lai, C.F. and Hu, B., 2016. Smart clothing: Connecting human with clouds and big data for sustainable health monitoring. Mobile Networks and Applications, 21(5), pp.825-845.

3. Paradiso, R., Faetti, T. and Werner, S., 2011, September. Wearable monitoring systems for psychological and physiological state assessment in a naturalistic environment. Annual International Conference of the IEEE Engineering in Medicine and Biology Society (pp. 2250-2253).

4. Wang, Z., Yang, Z. and Dong, T., 2017. A review of wearable technologies for elderly care that can accurately track indoor position, recognize physical activities and monitor vital signs in real time. Sensors, 17(2), p.341.

5. Villegas, A., McEneaney, D. and Escalona, O., 2019. Arm-ECG Wireless Sensor System for Wearable Long-Term Surveillance of Heart Arrhythmias. Electronics, 8(11), p.1300.

6. Majumder, S., Mondal, T. and Deen, M.J., 2017. Wearable sensors for remote health monitoring. Sensors, 17(1), p.130.

7. Wan, J., Al-awlaqi, M.A., Li, M., O'Grady, M., Gu, X., Wang, J. and Cao, N., 2018. Wearable IoT enabled real-time health monitoring system,EURASIP Journal on Wireless Communications and Networking, 2018(1), p.298.

8. Dekker, A.L.A.J., Datex-OhmedaInc, 2006. Monitoring physiological parameters based on variations in a photoplethysmographic signal. U.S Patent 7,001,337.

9. Laurie.G.Jacobs,Andrew Berman.,2003.,Respiratory disease in the elderly. Clinics in Geriatric Medicine 19(1) p.xi-xii

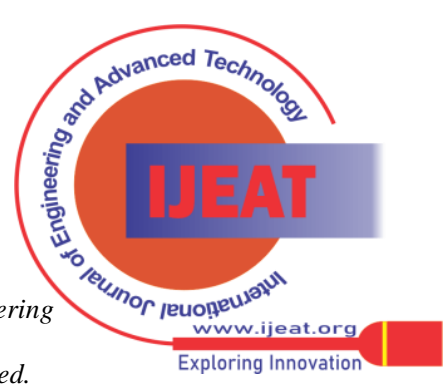


10. Ron Walls Robert Hockberger Marianne Gausche-Hill,2017, Rosen's Emergency Medicine: Concepts and Clinical Practice, $9^{\text {th }}$ edition

11. Audhild Hjalmarsen, Dan Levi Hykkerud.2008, Severe nocturnal hypoxaemia in geriatric inpatients, Age and Ageing, 37(5), p 526-529,

12. NIA Scientists,2018, Cold Weather Safety for Older Adults,National institute of Aging, https://www.nia.nih.gov/health/cold-weather-safety-older-adults\#

13. Michael Leavy,2019,How to prevent hypothermia in older people,Health professions press https://blog.healthpropress.com/2019/02/how-to-prevent-hypothermiain-older-people/>

14. Jessica Hegg,2016, Quick Look at Oxygen Saturation,Vive Health, $<$ https://www.vivehealth.com/blogs/resources/what-is-normal-oxygen-sa turation>

\section{AUTHORS PROFILE}

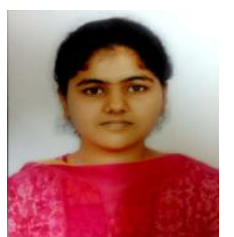

Ms. S. Lavanya, Final year student, Department of Biomedical Engineering, Sri Ramakrishna Engineering College was a Quarter-Finalist and the team leader in Indian Innovation Challenge Design Contest-2018 for the project Polysomnogram and in Indian Innovation Challenge Design Contest-2019 for the project Non-invasive bilirubinometer. She has published abstract of project work based on IOT based Medtex for Geriatric People in Emerging Innovations for Atmanirbhar Bharat (EIAB 2020) conducted by Bannariamman Institute of Technology - ISBN 978-93-5419-697-3. She has also obtained First Class with Exemplary for C Programming course conducted by Bharathidasan University under School-University-Industry- Tie-Up Scheme (SUITS) as a part of Institute for Entrepreneurship and Career Development in the academic year of 2012-2013.

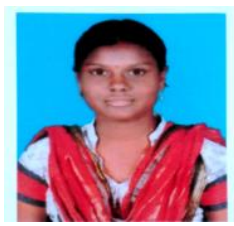

Ms. M. Madhumitha, Final year student, Department of Biomedical Engineering, Sri Ramakrishna Engineering College was a Quarter-Finalist in Indian Innovation Challenge Design Contest 2019 for the project Non-invasive bilirubinometer. She has participated in Internal Hackathon for Smart India Hackathon,2020. She, being an athlete, has also won first prize for relay as conducted by Annual Intra Mural Sports at Sri Ramakrishna Engineering College. She has also published abstract of project work based on IOT based Medtex for Geriatric People in Emerging Innovations for Atmanirbhar Bharat (EIAB 2020) conducted by Bannariamman Institute of Technology - ISBN 978-93-5419-697-3.

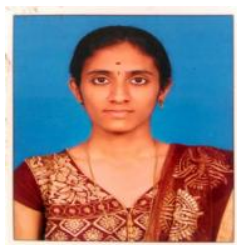

Ms. R. Srividhya, Final year student, Department of Biomedical Engineering, Sri Ramakrishna Engineering College was a Quarter-Finalist in Indian Innovation Challenge Design Contest 2018 for the project Polysomnogram and Quarter-Finalist in Indian Innovation Challenge Design Contest 2019 for the project Non-invasive bilirubinometer.She has participated in paper presentation at Sri Ramakrishna Institute of technology, Coimbatore and won "Best Paper Award" for the work Alumina as a Biomaterial. . She has also published abstract of project work based on IOT based Medtex for Geriatric People in Emerging Innovations for Atmanirbhar Bharat (EIAB 2020) conducted by Bannariamman Institute of Technology - ISBN 978-93-5419-697-3.

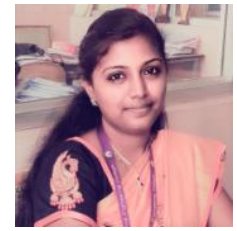

Ms. V. Srividhyasakthi, Assistant Professor, Department of Biomedical Engineering, Sri Ramakrishna Engineering College holds her M.E in Medical Electronics and a Bachelor's Degree in Biomedical Engineering with Distinction in affiliated colleges under Anna University, Chennai. She received India's Prestigious Gandhian Young Technological Innovation (GYTI) AWARD 2016, distributed during Festival of Innovation Inaugurated by former Honourable president of India Shri Pranab Mukherjee at Rashtrapati Bhavan, New Delhi.

She received fund from Biotechnology Industry Research Assistance Council (BIRAC), Society for Research and Initiatives for Sustainable Technologies and Institutions (SRISTI).She has published 5 papers in

Published By:

Blue Eyes Intelligence Engineering and Sciences Publication

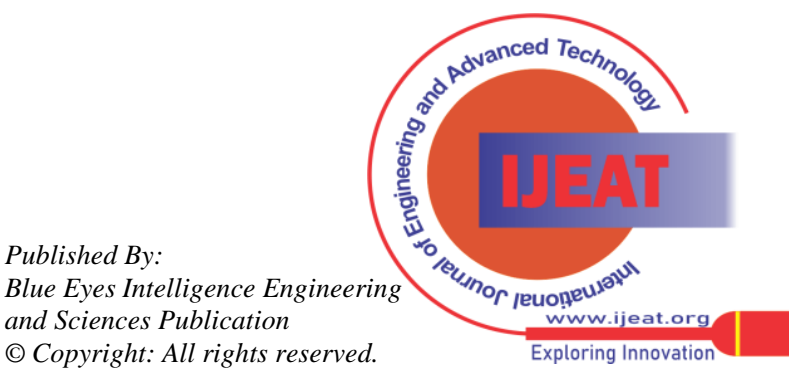

